\title{
Factors Influencing Strategy Implementation: A Study on Oromia International Bank, North West Showa (NWS) District, Ethiopia
}

\author{
Addisalem Tadesse Bogale ${ }^{1^{*}} \quad$ Belay Adamu Dunfa $^{2} \quad$ Fanta Tariku Wadajo $^{1}$ \\ 1.Lecturer of BAIS, College of Business and Economics, Department of Business Administration and \\ Information System (BAIS), Ambo University, Woliso campus \\ 2.Lecturer of Marketing management, College of Business and Economics, Department of Marketing \\ Management, Ambo University, Woliso Campus
}

\begin{abstract}
The importance of strategy to a firm cannot be gainsaid. The fact that financial institutions have strived from various stages alongside the adoption of various organizational strategies indicates that it has not been easy to achieve optimum strategy implementation. The motive of this study was to examine factors influencing strategy implementation at Oromia International bank NWS district. Based on different literature the identified factors were: age, sex, experience, education, organizational culture, organizational structure, organizational process, and leadership and employee commitment. The result of multiple linear regression model moreover revealed that organizational culture, organizational structure, leadership and employee commitment were significant for strategy implementation of OIBNWSD with $\beta$ value $.262, .127, .047$ and .056 respectively. Based on the research results, it was recommended for OIBNWSD bank's in study area to improve the influence of strategy implementation factors dimensions through providing training to their leaders and employees, allocating resource based on relative importance of factors, carrying out depth research on strategy implementation influencing factors, continuously evaluating factors influence and giving prioritize for employees' needs.
\end{abstract}

Keywords: Culture, Structure, Process, Leadership and Commitment

DOI: $10.7176 / \mathrm{EJBM} / 11-34-01$

Publication date: December $31^{\text {st }} 2019$

\section{Introduction}

Although many studies depict that strategies often fail not because of insufficient strategy formulation, but because of insufficient implementation, strategy implementation has attracted less research than strategy formulation. It involves the design and management of systems to achieve the best integration of people, structures, processes and resources in achieving organizational objectives. Yet the implementation of a strategy is not easy (Pfeeffer \& Salancik, 2003). Many researchers have identified factors that affect strategy implementation such as corporate ownership and commitment (Raps, 2005). (Kaplan and Norton 2005) believed that 95 percent of company's employees are unaware of or don't understand their company's strategy.

Setting the organizational climate relevant for strategy implementation is important for making strategy work (McKinley and Scherer, 2000). Organizations whose strategy is implemented within conducive environment are more effective as compared to those whose are not (Wai-Kwong, Priemn, \& Cycyota, 2001). According to Alexander (1985), the most often occurring strategy implementation difficulties include underestimating the time needed for implementation and key problems surfacing initially not anticipated. With regard to people, the capabilities of employees involved were often not sufficient, leadership and direction and "training and instruction given to lower level employees were not adequate" (Alexander, 1985).

\section{Statement of the problem}

Okumus (2001) noted that despite the importance that strategy execution process has, more research has been carried out into strategy formulation while few have been carried out with regard to strategy implementation. The indifference to strategy implementation can be credited to several reasons which include: greater likelihood of failures in strategies' implementation; higher complexity in strategy implementation process; the perception that strategy implementation is less desirable than formulation; and practical challenges in research involving middlelevel managers (Alexander, 1985).

There was gap still exists between knowing what to do and actually doing it. Hrebiniak (2006) argues that most managers know far more about developing strategy than they do about executing it. As a result, they spend a lot of time formulating their strategies but often find that almost nothing ultimately changes in their companies. According to David (2003), elements to be looked during strategy implementation are; policies, objectives, conflict management, resource allocation, organization structure, organization culture, and ability to manage resistance to change. Parnell (2008) explains strategy implementation through the concepts of participation, conception, and commitment that affect the dissemination of the strategy. Therefore, strategy implementation is a complex process 
(Schellenberg, 1983).

The surveyed respondents understood and replied as the Oromia International Bank, NWS district strategically plans more but practical accomplish less in real phenomena. In this study context the fact that financial institutions have struggled from various stages alongside the embracing of diverse organizational strategies indicates that it has not been easy to attain optimal strategy implementation. In addition when the researcher see the gap of the literature there was no previous studies conducted on this topic and $t$ in the Zone and the study examine the current status of strategy implementation and the factors that influence strategy implementation at grass root level or district level which may vary from area to area.

Therefore, there is the need to research on factors influencing strategy implementation at Oromia International Bank NWS district is a reason which contributes to the researcher's interest in conducting the study. Thus the main objective of the study was to assess factors that influence strategy implementation in OIBNWSD. Based on this, the study aims to answer the following questions:

1. What is the effect of an organizational process on strategy implementation at OIBNWSD?

2. What is the influence of an organizational culture on strategy implementation?

3. What is the influence of an organizational structure on strategy implementation?

4. What is the effect of leadership on strategy implementation?

5. What is the influence of an employee commitment on strategy implementation?

\section{Research Hypotheses}

In order to answer the research question study, literatures review of previous studies were conducted to drive the hypothesis based on existing knowledge and the following hypotheses were developed for this research, that are: H1: Organizational process effects strategy implementation at Oromia International Bank, NWS District

$\mathrm{H} 2$ : Organizational culture influences strategy implementation at OIBNWSD

H3: Organizational structure influences strategy implementation

H4: Leadership effects on strategy implementation

H5: Employee commitment influences strategy implementation

\section{Literature Review}

The empirical literature survey helps the development of the theoretical framework and hypothesis for testing. There have been a lot of studies conducted on the topic and the following were the summary of some of them:

Organizational process includes operational planning, resource allocation, people, communication, control and feedback. The various processes have an impact on each other in one way or the other. For instance, the process of project initiation and operational planning of the implementation activities affect communication, the resource allocation, and the provision of training and incentives. Places emphasis on the need to use clear multiple modes of communication (top-down, bottom-up, lateral, formal informal, internal, external, one time and continuous communication) to communicate the new strategy within and outside the organization. The efforts and results of the implementation are to be monitored and compared against predetermined objectives. The operational plans and communication are regarded as key to monitoring the process (Okumus, 2001).

Ahuja (2003) indicated that executing strategy implies marshaling employees alongside managers in order to put formulated strategies into action. Successful strategy implementation requires discipline, commitment, sacrifice and tests manager's ability to motivate employees. Interpersonal skills are critical for a successful strategy implementation. Implementation affects all employees and employers in an organization. Each segment of an organization must position them to answer questions such as actions to be taken to implement their part of the organization's strategy (Ahuja, 2003).

Culture: Organizational culture refers to the leadership style of managers. This is with regard to their timespending, their focus, questions towards their employees, their decision-making; and organizational culture. Leadership also entails their dominant values and beliefs, the personal and organization norms, and conscious and unconscious symbolic acts which may include dress codes, job titles, and informal meetings with employees (Adkins \& Caldwell, 2004). Organizational culture includes the shared beliefs, norms and values within an organization. It sets the foundation for strategy.

Structure: Most companies are configured in terms of four basic elements of organizational structure. These are namely; span of control, centralization, formalization and departmentalization. The most necessary elements to describe the shape of an organization are its breadth and depth (Colombo and Delmastro 2002). The depth defines the number of hierarchical layers or management levels that lay between the top management and operational employees. The breadth could be measured by the control span, that is, the number of a supervisor's direct reports or subordinates. The span of control can be calculated at each hierarchical layer, but it can also be averaged across the levels of an organization. Obviously, there exists an inverse affiliation between depth and breadth, given to an organization's size.

Leadership: Leadership is the capability to influence individuals to achieve defined objectives. According to 
Hitt et al. (2001), strategic leadership significantly contributes to strategy implementation and the overall performance of organizations. Strategists have a vital role to play by exercising leadership to mobilize the resources of the organization and guiding others toward a definitive objective. According to Cater and Pucko (2010), while a well-formulated strategy, a strong and effective pool of skills, and human capital are extremely important resources for strategy success, poor leadership is one of the main obstacles in successful strategy implementation.

Employee Commitment: Commitment is considered to be psychological immersion of an individual with his institute through sense of belonging, ownership of organizational goals and being ready to accept challenges (Dolan,Tzafrir, and Baruch,2005). Creating commitment among employees is important because without this it will become difficult for an organization to achieve strategic goals.(Brisco and Claus,2008;Fugate,etal.,2009).

\section{Research design}

The study employed cross-sectional design which had been taking study with in a particular timeframe.For the purposes of this study, the researcher employed descriptive and explanatory research designsto fulfil the objectives of the research. Descriptive research design was employed for the data that the researcher collected from respondents through questionnaire and interview and more appropriate to detail description of the findings displayed in tables. The target populations for the study were the employees who work at Oromia International Bank NWS district. According human resource department of NW district of Oromia International Bank information, there were 1381 total employees at Oromia International Bank, NWS district who working for the organization's existence and sustainability. Respondents (OIBNWSD employees) were selected through simple random sampling techniques (lottery method) to draw representatives used by taking in to account the homogeneity in terms of the associated elements and working environment strategy implementation takes place to select the subject under study.

\section{Model specification}

To analyze the data, different kinds of statistical methods including descriptive statistics, and inferential statistics (correlation and multiple linear regressions) were employed to identify and predict the relation and contribution each of the significant predictors for the study objectives. Finally, the results of both descriptive as well as inferential results were presented by appropriate figures and tables. Thus, the following multiple linear regression was developed to make the research more effective in analyzing the influences of independent variables (organizational culture, organizational structure, organizational process, and leadership and employee commitment) on the dependent variable (Strategy Implementation).

Gujarati (1995) defines regression as follows

$$
\mathrm{Y}=\beta 0+\beta 1 \mathrm{X} 1+\beta 2 \mathrm{X} 2+\beta 3 \mathrm{X} 3+\beta 4 \mathrm{X} 4+\beta 5 \mathrm{X} 5+\mathrm{ui}
$$

Where, $Y=$ the dependent variable in the model, $X 1=$ organizational culture, $\mathrm{X} 2=$ organizational structure, $\mathrm{X} 3=$ organizational process, $\mathrm{X} 4=$ leadership and $\mathrm{X} 5=$ employee commitment in the estimation model,

$\boldsymbol{\beta 0}=$ is the constant,

$B n$ is the coefficient of independent variables,

$\mathrm{Xn}$ is independent variables,

$\mathbf{u i}=$ is the error term.

ui $=\mathrm{Y}-\beta 0-(\beta 1 \mathrm{X} 1+\beta 2 \mathrm{X} 2+\beta 3 \mathrm{X} 3+\beta 4 \mathrm{X} 4+\beta 5 \mathrm{X} 5)$

Multiple linear regression assumptions were conducted based on Gujarati (1995) and Fidell (2001). Checking goodness of-fit carry significant benefits for the research; because once the model is fitted it is effective in describing the outcome of variables. 


\section{Result and discussion}

Table 1: Pearson Correlation Coefficient Matrix

\begin{tabular}{|c|c|c|c|c|c|c|}
\hline & 1 & 2 & 3 & 4 & 5 & 6 \\
\hline Strategy implementation & 1 & & & & & \\
\hline Organizational Culture & $\begin{array}{c}.859^{* *} \\
.000\end{array}$ & 1 & & & & \\
\hline Organizational Structure & $\begin{array}{r}.699^{* *} \\
.000\end{array}$ & $\begin{array}{c}.568^{* *} \\
.000\end{array}$ & 1 & & & \\
\hline Organizational Process & $\begin{array}{r}.335^{* *} \\
.000\end{array}$ & $\begin{array}{r}.381^{* *} \\
.000\end{array}$ & $\begin{array}{r}.271^{* *} \\
.000\end{array}$ & 1 & & \\
\hline Role of Leadership & $\begin{array}{r}.404^{* *} \\
.000\end{array}$ & $\begin{array}{c}.325^{* *} \\
.000\end{array}$ & $\begin{array}{c}.363^{* *} \\
.000\end{array}$ & $\begin{array}{r}.309^{* *} \\
.000\end{array}$ & 1 & \\
\hline Employee Commitment & $\begin{array}{r}.365^{* *} \\
.000\end{array}$ & $\begin{array}{c}.286^{* *} \\
.000\end{array}$ & $\begin{array}{r}.333^{* *} \\
.000\end{array}$ & $\begin{array}{r}.359^{* *} \\
.000\end{array}$ & $\begin{array}{r}.411^{* *} \\
.000\end{array}$ & 1 \\
\hline
\end{tabular}

**. Correlation is significant at the 0.01 level (2-tailed) $\mathrm{N}=297$

Source: own survey result, 2019

According to the above table, there is a positive relationship between strategy implementation and organizational culture, organizational structure, organizational process, role of leadership and employee commitment with magnitude of $0.859,0.699,0.335,0.404$ and 0.365 respectively. The positive relationship indicates that there is a correlation between the factors and strategy implementation in Oromia International Bank North West Showa district with organizational culture having the highest value and organizational process having the lowest correlation value.

This notwithstanding, all the factors had a significant $p$-value $(p<0.05)$ at $95 \%$ confidence level. The significance values for organizational structure, organizational culture, organizational process, leadership and employee commitment all were 0.00 . This indicated that all the factors were significant.

Table 2: Multicollinearity Statistics

\begin{tabular}{lcc}
\hline & \multicolumn{2}{c}{ Collinearity Statistics } \\
\cline { 2 - 3 } (Constant) & Tolerance & VIF \\
Organizational Culture & & 1.623 \\
Organizational Structure & .616 & 1.593 \\
Organizational Process & .628 & 1.292 \\
Role of Leadership & .774 & 1.333 \\
Employee Commitment & .750 & 1.339 \\
\hline
\end{tabular}

a Dependent Variable: Strategy implementation

Source: own survey data, 2019

Above table 2 shows the computation result that the value of VIF all variables were by far less than 10 and the value of tolerance statistics being above 0.1 they were accepted entered in to regression model for the estimation of variable.

Table 3: Analysis of Variance (ANOVA)

\begin{tabular}{lllllll}
\hline \multicolumn{2}{l}{ Model } & Sum of Squares & Df & Mean Square & F & Sig. \\
\hline 1 & Regression & 19.157 & 5 & 3.831 & 253.233 & $.000^{\mathrm{b}}$ \\
& Residual & 4.403 & 291 & .015 & & \\
\hline
\end{tabular}

Dependent Variable: Strategy implementation

Predictors: (Constant), Employee commitment, Organizational culture, Organizational process, Organizational structure, Role of leadership

Source: survey result, 2019

As indicated in table 3 the total sum of square (23.560) is equal to the sum of regression sum of square (19.157) and residual sum of squares (4.403). The study of these total sum squares is known as analysis of variance (ANOVA) from regression point of view.

From the above table 3 , it is identified that the value of F-stat is 253.233 (mean square of regression divided by mean square of residual) and it is significant at $p$-value of $0.00(p<0.05)$. This indicates that the overall model was reasonably fit and there was statistically significant association between strategy implementation influencing factors dimension and strategy implementation. Hence, it can be concluded that strategy implementation influencing factors (implementation factors) have significant influence on strategy implementation of Oromia International Bank, North West Showa district. The beta coefficient was indicated as the following table. 
Table 4: Regression Coefficients

\begin{tabular}{|c|c|c|c|c|c|}
\hline \multirow[t]{2}{*}{ Model } & \multicolumn{2}{|c|}{$\begin{array}{l}\text { Unstandardized } \\
\text { Coefficients }\end{array}$} & $\begin{array}{l}\text { Standardized } \\
\text { Coefficients } \\
\end{array}$ & \multirow[t]{2}{*}{$\mathbf{T}$} & \multirow[t]{2}{*}{ Sig. } \\
\hline & $\mathbf{B}$ & Std. Error & Beta & & \\
\hline (Constant) & 2.119 & .095 & & 22.354 & .000 \\
\hline Organizational Culture & .262 & .013 & .674 & 20.882 & .000 \\
\hline Organizational Structure & .127 & .014 & .281 & 8.792 & .000 \\
\hline Organizational Process & -.017 & .012 & -.043 & -1.484 & .139 \\
\hline Role of Leadership & .046 & .020 & .069 & 2.367 & .019 \\
\hline Employee Commitment & .056 & .025 & .065 & 2.231 & .026 \\
\hline
\end{tabular}

Dependent Variable: Strategy implementation

Significant $\mathrm{p}$ - value $<0.05 \%, \mathrm{p}<0.01$

Source; survey result, 2019

The dependent variable $(\mathrm{Y})$ and independent $(\mathrm{X})$ variables relationship can explain as;

$\mathrm{Y}=\beta 0+\beta 1 \mathrm{X} 1+\beta 2 \mathrm{X} 2+\beta 3 \mathrm{X} 3+\beta 4 \mathrm{X} 4+\beta 5 \mathrm{X} 5+\mathrm{e}$, Where $\beta 0$ is constant, $\beta \mathrm{n}$ is the coefficient of independent variables (Satendra et, 2011). The researcher used un standardized beta coefficients to compare or prioritize the effect of independent variables on dependent variable and to construct regression equation. If we substitute the coefficient from the above table the equation becomes;

Strategy implementation $=2.119+0.262$ organizational culture +0.127 organizational structure $+(-.017)$ organizational process +0.046 role of leadership +0.056 employee commitment.

From this we can understand that the marginal values provide the impact that a unit change in the individual independent variables has on different strategy implementation when other variables are held constant. Four variables were significant as their significant values was less than $(\mathrm{p}<0.05)$.

\section{Conclusion}

The study concluded that Organizational Culture positively influences Strategy Implementation to a great extent at OIBNWSD. To this end the study found that Oromia International Bank North West Showa District has a clearly defined vision and mission statements. The study further revealed that there is clarity of vision and mission statements among employees through the bank. The study also revealed that the bank has culture of tolerating risks and risk tolerance helped in strategy implementation in the bank. The study finally discovered that the bank tolerates new ideas and the tolerances of new ideas enhance strategy implementation at study area banks. Thus the study concluded that Organizational Culture influence Strategy Implementation at OIBNWSD and vice versa is also true if the culture is not healthy.

The study further concluded that Organizational Structure influence Strategy Implementation in Oromia International Bank North West Showa district. The study discovered that the current structure of Oromia International Bank has clear lines of authority and the current organizational structure enhances institutional effectiveness. The study further established that to enhance Strategy Implementation success, the organization selects the right people for key positions and the nature of their organizational structure enhances organizational flexibility critical to strategy implementation. Thus, the study concluded that Organizational Structure influence Strategy Implementation at Oromia International Bank North West Showa District.

The study moreover revealed that Leadership effect Strategy Implementation in Oromia International Bank North West Showa District. To this end the study discovered that Oromia International Bank North West Showa District that the leadership style in their bank does support banking profession, the leadership style is sensitive and supportive of banking profession, the bank's leadership does allow for banker's input in the decision making process and leadership motivate employee to demonstrate commitment toward strategy implementation. Thus the study concluded that Leadership affects Strategy Implementation at Oromia International Bank North West Showa District.

The study finally noted that success of Strategy Implementation positively influence by Employee Commitment at Oromia International Bank North West Showa District. To assure this research ascertained that Employees feel that they have too few options to consider leaving this bank; they continue to work for this bank because leaving would require considerable personal sacrifice and they really feel as bank's problems are their own. Thus the study revealed that Employee Commitment influence Strategy Implementation at Oromia International Bank North West Showa District.

\section{References}

[1] Adkins, B., \& Caldwell, D. (2004). Firm or subgroup culture: Where does fitting in matter most? Journal of Organizational Behavior, 25, 969-978

[2] Ahuja, J. (2003). Identity management: a business strategy for collaborative commerce. Information Systems Control Journal, 6, 1-5 
[3] Alexander, L. D. (1985). Successfully implementing strategic decisions. Long range planning, 18(3), 91-97

[4] Briscoe, D. R., \& Claus, L. (2008). Employee performance management: policies and practices in multinational enterprises. Performance Management Systems: A Global Perspective, Routledge, London, 1539.

[5] Cater, T., \&Pucko, D. (2010). Factors of effective strategy implementation: Empirical evidence from Slovenian business practice. Journal for East European Management Studies, 15(3), 207-236.

[6] Colombo, M. G., \& Delmastro, M. (2002). How Effective are Technology Incubators?: Evidence from Italy. Research Policy, 31, 1103-1122.

[7] David, F.R. (2003).Strategic Management Concepts. $9^{\text {th }}$ Edition, London: Prentice Hall.

[8] Dolan, S. L., Tzafrir, S. S., \& Baruch, Y. (2005).Testing the causal relationships between procedural justice, trust and organizational citizenship behavior.

[9] Hitt et al, 2001, Strategic management: Competitiveness and Globalization, books, south western publishing, 6 th edition

[10] Hrebiniak, L.G. (2006). Obstacles to Effective Strategy Implementation. Organizational Dynamics, 35, $12-$ 31.

[11] Kaplan R., S., \& Norton D. P. (2005).Linking the Balanced Scorecard to Strategy. California Management Review, 39(1), Fall. https://doi.org/10.2307/41165876

[12] Mckinely and Scherer. (2000).Some unanticipated consequence of organizational restructuring, Academy of Management Review, Vol 25 No. 4: pp. 735-752

[13] Okumus, F. (2001).Towards a Strategy Implementation Framework. International Journal of Contemporary Hospitality Management, 13, 327-338

[14] Parnell, J. A. (2008). Strategy execution in emerging economies: assessing strategic diffusion in Mexico and Peru, Management Decision, 46 (9), 1277-1298

[15] Pfeeffer, J. \& Salancik, G. R. (2003 [1978]). The External Control of Organizations: A Resource Dependence Perspective. Stanford: Stanford University Press.

[16] Raps, A. (2005). Strategy implementation: An Insurmountable Obstacle? Handbook of Business Strategy, 6, $141-146$.

[17] Satendra K.M. (2011). Development and Regulation, McGraw-Hill

[18] Schellenberg, D. S. (1983). Issues in strategy implementation: The effect of congruence among strategy, structure, and managerial performance criteria on organizational performance. Doctoral dissertation, Indiana University

[19] Wai-Kwong, F.Y., Priemn, R.L. \& Cycyota, C.S. (2001). The performance effects of human resource managers' and other middle managers' involvement in strategy making under difference business-level strategies: the case of Hong Kong. International Journal of Human Resource Management, 12, 1325-46 